\title{
Prevalence of Physical Activity, Sedentary Behaviour and Unhealthy Dietary Habits among Moroccan Adolescents
}

\author{
Abdelmounaim Boulhanna ${ }^{a^{*}, \text { Hammou Anarghou }}{ }^{\mathrm{b}}$, Said Ihbour $^{\mathrm{c}}$, Mohamed Najimi ${ }^{\mathrm{d}}$, Fatiha \\ Chigr $^{\mathrm{e}}$ \\ ${ }^{a *}$ Laboratory of Biological Engineering, Faculty of Science and Technology, Sultan Moulay Slimane University, \\ Beni Mellal, Morocco. E-mail: boulhanna.abdel@gmail.com \\ b,c,d,e Laboratory of Biological Engineering, Faculty of Science and Technology, Sultan Moulay Slimane \\ University, Beni Mellal, Morocco.
}

Article History: Received: 11 January 2021; Accepted: 27 February 2021; Published online: 5 April 2021

\begin{abstract}
Adolescence represents a very crucial phase in the human life cycle. During this period adolescents develop individual lifestyle habits. as a result, and in the absence of data concerning the above characteristics, in the Beni Mellal-Khénifra region, we leaded a cross-sectional survey of growth ,food and hygiene behaviour conducted among a sample of 812 adolescents, including 404 boys attending school aged 13 to18 years, Furthermore, the objective of this study was also to verify among college students of the region the prevalence of moderate physical activity levels, unhealthy dietary habits and sedentary behaviour, in order to determine the risk factors related to the physical inactivity. The prevalence of physical activity was $36.08 \%$ (50.0\% among boys and $22.06 \%$ among girls). Nearly $40 \%$ of these adolescents spend more than 2 hours a day in front of the screens. Unhealthy dietary habits are more frequent among adolescents and the majority of them consume Fried potatoes (fries and chips) Doughnuts/cake, Sugary drinks more than three times a week. These results show significant associations between physical activity, sedentary habits and some unhealthy dietary habits.
\end{abstract}

Keywords: Physical Activity, Sedentary Behaviour, Unhealthy Dietary Habits, Adolescent, Morocco.

\section{Introduction}

The advantages of a healthy lifestyle are well-recognized. They reduced the risk of obesity, type II diabetes, coronary heart disease and stroke, and also colon and breast cancer. Consequently, more than 1.9 million at the global deaths per year could be prevented if everyone was sufficiently physically active. (BullFC, 2004) (WHO, 2005). Studies on the effects of sedentary lifestyles on human health have increased considerably over the last decade. A considerable body of epidemiological evidence now indicates that individuals who engage in sedentary behaviour on a high volume regardless of their physical activity levels, are at increased risk of disease and death (Proper, 2011). This phenomenon described initially in developed countries has now reached also developing ones as these latters changed radically their life style or are in nutritional transition (Popkin, 1994). In parallel, this transition has been accompanied by epidemiological transition (Omran, 2005). Morocco like other neighbouring developing countries is experiencing now these two transitions (Benjelloun, 2002); (Ben Romdhane, 2002). In this context, it is of high importance to evaluate sedentary and physical activity status in Moroccan population to relate it to reported health problems. Therefore, the purpose of our study is to report on the prevalence of moderate physical and sedentary activity, and unhealthy dietary habits among Moroccan adolescents in secondary school, which generally covers an age ranging from 13 to 18 years. These formative years of adolescence represent a decisive phase in the human life cycle, as they are the stage when lifestyles are well established, during which adolescents become more autonomous and have more access to lifestyle choices. Adolescents also increase their social interaction with their peers of the same age and develop individual lifestyle habits patterns.

\section{Methods}

\section{Participants}

The results presented in this work come from a cross-sectional survey of growth and dietary and hygienic behaviour carried out in the Beni Mellal Khénifra region. The sample consists of 812 school-going adolescents, including 404 boys, aged 13 to 18 years. The data were collected during January to June 2018 a face-to-face interview with participants by the authors of this study using questionnaire. All participants have given their informed consent, and we have been authorized by the National Ministry of Education to do this work.

\section{Measurement of Physical Activity Levels}


The measure of physical activity levels is the total number (in minutes or hours) of moderate-intensity physical activities per day or per week, these activities have been assigned an average MET (metabolic equivalent of the task) equivalent to 4 METs, these values based on the compendium of physical activity. (BARBARAE, 2011) and the Youth Physical Activity Compendium (Nancy F, 2017). The Guidelines for adolescents recommend a minimum of $60 \mathrm{~min}$ Moderate-intensity physical activities per day or $1680 \mathrm{METs}$. min per week. (Prochaska JJ, 2001); (WHO.2017). The total amount of activity per week was then expressed in MET. Minutes per week using four 4 METs for moderate-intensity activity. Adolescents were classified as active or inactive basing on a total of 1680 minutes METs per week, which corresponds to one 1 hour of moderateintensity daily physical activity (Al-Hazzaa, 2011). (Al-Hazzaa, 2011). Finally, the maximum time spent in physical activity was truncated to fort 4 hours (h) per day or 28 hours per week.

\section{Sedentary Activity and Sleeping Hours}

The questionnaire includes also sedentary behaviour, such as daily time spent using a computer and viewing television, indeed the recommended daily time is limited to two hours by the guidelines of the American Academy of Paediatrics (American Academy of Paediatrics, 2001). The maximum time devoted to sedentary behaviour was used to classify our population into two categories based to the time expended in front of these screens: ( $\leq 2$ hours per day and $>2$ hours a day ( $/ \mathrm{d}$ ), furthermore the time of sleep per day (night and day).

\section{Unhealthy Dietary Habits}

Dietary habits have been classified as healthy eating habits, like consumption of fruits, vegetables, breakfast, etc. more or equal seven times per week ( $\geq 7$ times/week), and unhealthy habits such as consumption of French fries (fries and chips), fast food, donuts/cakes, energy and sweetened drinks more than three times per week (> 3 times/week).

\section{Statistical Analysis}

Data have been analysed using the SPSS Statistics statistical software (version 19.0.) And Microsoft Office Excel (Version 2016). In addition, data were presented as percentages and 95\% confidence intervals, medians and interquartile ranges (25th-75th percentile). We used The Mann-Whitney U test to compare medians between boys and girls and the chi-square $\chi 2$ or Fisher's test to determine $\mathrm{P}$ values between nominal variables. The test was considered significant when the $\mathrm{P}$ value was less than 0.05 .

\section{Results}

A total of 812 adolescents participated in this study (50.24\% girls) with a median age of 15 years. The levels of moderate physical activity; time (total hour per week) and energy expenditure (total MET-min per week) have been assessed and presented in Table 1. Overall, physical activity levels differed by gender, with boys being on average more physically active than girls. Indeed, the total MET-min per week score was higher for boys than girls with a very significant difference $(\mathrm{P}=0.000)$. In addition, a significant proportion of boys achieved the recommended moderate physical activity level than girls ( $\geq 1680$ MET-min/week), with respective prevalence of $50.25 \%$ and $22.06 \%$ (Figure 1).

Concerning sedentary traits, almost $40 \%$ of the sample reported television watching for more than 2 hours a day(h/d) and $31 \%$ engaged in computer use for a similar period, compared to boys, $45 \%$ of girls spend more than two hours per day viewing television with a very significant difference between the two sexes $(\mathrm{P}=0.010)$ (Table 2).

When unhealthy eating habits are concerned, most adolescents surveyed reported consuming fast food, French fries (fries and chips), donuts/cakes, energy and sugary drinks up to three times a week. The proportions of consumption of French fries, cakes and sweet drink are approximately high; The respective prevalence's are $40 \%, 58 \%$ and $45 \%$. By gender, the difference is therefore significant for all three types of food because girls take more doughnuts/cakes $(p=0.000)$, French fries (fries and chips) $(p=0.000)$, and fast food $(p=0.014)$ than boys. On the other hand, no significant differences were observed in the consumption of sugary and energy drinks, furthermore Relatively lower proportions of boys and girls consuming energy drinks more than 3 days a week, the respective prevalence's are (1.8\%) and (2.1\%). 
Table 1. The time spent on moderate physical activity among Moroccan adolescents. ${ }^{1}$ The Mann-Whitney U test was used to compare medians between boys and girls. MET, metabolic equivalent of task. IQR, interquartile range (25th-75th percentile).

\begin{tabular}{lllllll}
\hline & All (812) & \multicolumn{3}{c}{ Boys (404) } & \multicolumn{3}{c}{ Girls (408) } \\
\hline & Median & Median & IQR & Median & IQR & P value $^{1}$ \\
Age (years) & 15 & 15 & $14-17$ & 15 & $14-16$ & .000 \\
Moderate physical activity measures & & & & & & \\
MPA measures Total (h/w) & 3.5 & 5.00 & $3.50-16.90$ & 3.50 & $2.10-4.00$ & .000 \\
MPA measures Total MET.min/week & 1320 & 1680 & $1320-4536$ & 1320 & $984-1440$ & .000 \\
MPA $\geq 1680$ MET. Min/Week & 3888 & 4464 & $2880-6720$ & 3000 & $2160-4800$ & .000 \\
\hline
\end{tabular}

Table 2. The time spent on sedentary behaviour among Moroccan adolescents. the findings are presented in percentages (\%). ${ }^{1}$ Bootstrap results were based on 1000 bootstrap samples for total proportions. ${ }^{2}$ chi-square $\chi 2$ or Fisher test was utilized to calculate $\mathrm{P}$ values between nominal variables.

\begin{tabular}{llllll}
\hline & All (812) & $95 \%$ CI $^{1}$ & Boys (404) & Girls (408) & Pvalue $^{2}$ \\
\hline Sedentary behaviour & 40.4 & $36.7-43.6$ & 35.8 & 44.7 & .010 \\
Tv viewing $>$ 2h/d & 31.2 & $28.1-34.4$ & 28.8 & 33.5 & .152 \\
Computer use> 2h/d & 38.9 & $35.8-42.2$ & 34.1 & 43.6 & .006 \\
Total (TV viewing and computer use) $>$ 2h/d & 38.0 & $34.9-41.4$ & 37.0 & 39.2 & .526 \\
Sleeping < 7 (h/d) & &
\end{tabular}

Finally, concerning the sleeping time duration, $38 \%$ of adolescents report that they have an average sleep time of less than 7 hours per day. However, no significant difference was observed for the average sleep duration between girls and boys.

\section{Discussion}

This study reported moderate physical activity levels, eating habits (unhealthy habits) and sedentary time of adolescents schooling in the Beni Mellal-Khenifra region of Morocco. Generally spoken, few studies have characterized. However, to our awareness there are no other studies that would have identified the lifestyle habits mentioned before among the population of the Beni Mellal Khenifra region.

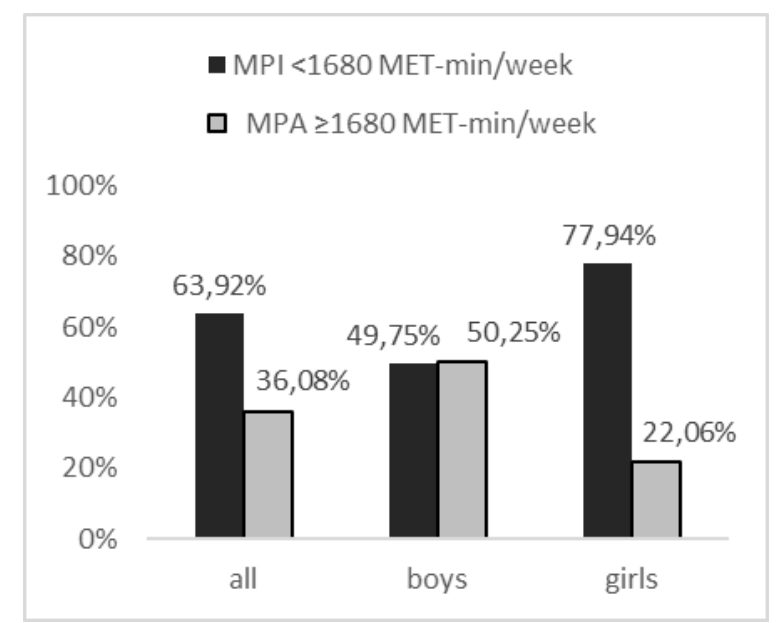

Figure 1. Levels of physical inactivity and activity among Moroccan adolescents (404 boys and 408 girls). A very high significant difference between boys and girls for physical inactivity $(\mathrm{P}=0 \cdot 000)$.

Indeed, our study has revealed some important points, particularly: $77.94 \%$ of the girls and half of the boys $(49.75 \%)$ are physically inactive and don't meet the current global recommendation for physical activity a minimum of 60 min Moderate-intensity physical activities per day or 1680 MET. Mint per week. (Prochaska JJ, 2001); (WHO, 2010). (Figure 1). Almost all (38.9\%) of the boys and girls spend more than $2 \mathrm{~h} / \mathrm{d}$ on sedentary activities (TV viewing and computer use). (table2). $3)$.

A significant prevalence of the students in the region who have an unhealthy dietary pattern is present. (table

More than one third of these adolescents have average sleep duration of less than 7 hours per day (table2). 
The overall prevalence of PA (36.0\%) in this population was less than the score of (78.91\%) reported by Hamrani in Kenitra city (Hamrani, 2015) and that of $42.2 \%$ declared by El Achhab in Taza city (El Achhab, 2018), although this score is not so far different from our findings. Interestingly, the observed results are similar to those reported in Saudi and Kuwaiti adolescents, (Allafi, 2014), (Al-Hazzaa, 2014) and among Qatari adolescents (Al-Thani, 2018). Compared to the adolescents in Taza city, we have almost the same results for both genders, however most boys $(91.4 \%)$ and girls $(67.1 \%)$ in Kenitra city met the current global physical activity guidelines which are a minimum of one hour of moderate-intensity physical activity a day or 1680 METs.min per week. The difference between our study and that performed by Hamrani in Kenitra city may be explained by the socio-economic distinction between the two regions. The city of Kenitra is situated in the large industrial pole, in the western north of Morocco; it is a province in the Moroccan economic region of Rabat-SaléKhénifra, an important economic pole with agricultural, industrial, tourism and service opportunities and a crucial element in the realization of regional development. Furthermore, this region is characterized by the availability of places to practice physical activities and sport centres which encourages sport practices. In contrast, Beni Mellal region is located in a disadvantaged socio-economic region which suffers from a virtual absence of industrial units, with low economic and social development and weak level of infrastructures dedicated to physical activity and sport practices. Nevertheless, cultural traits could also explain these differences as in Kenitra city, sport practices in general is a part of life styles of the population which is different from that of Beni Mellal's population region where rural culture subsists strongly, this is also well illustrated when gender is concerned. Indeed, our results revealed that two out of three adolescents were classified as inactive; or $78 \%$ of girls versus $50 \%$ of boys. The difference in moderate physical activity levels between males and females in our population may be due to several cultural reasons such us where families cannot push and encourage girls to participate in activities outside of school. In addition, girls, compared to boys in general have limited opportunities and facilities for the practice of physical activities. The culture of sports practice for girls is still alien to society. This is due as cited above to the particularity of the region semi-rural character, as well as the lack of sports space for this gender in which girls practice sports in absolute comfort. On the other hand, the girl takes advantage of this free time and turns to sedentary activities such as TV watching, video games playing, surfing in the internet, etc. In connection with this, our findings revealed that $31 \%$ of adolescents use the computer and nearly $40 \%$ spend more than two hours a day $(\mathrm{h} / \mathrm{d})$ television watching, for a similar period. Furthermore, we found that girls were less active than boys, particularly in moderate activities, and they also spend more time in sedentary activities.

Table 3. unhealthy dietary habit profiles among Moroccan adolescents, the findings are presented in percentages (\%). ${ }^{1}$ Bootstrap results were based on 1000 bootstrap samples for total proportions, ${ }^{2}$ The chi-square $\chi 2$ or Fisher test was utilized to calculate $\mathrm{P}$ values between nominal variables.

\begin{tabular}{llllll}
\hline & All (812) & $95 \% \mathrm{CI}^{1}$ & Boys (404) & Girls (408) & Pvalue $^{2}$ \\
\hline Unhealthy dietary behaviour (>3times/week) & 40.9 & $37.7-44.6$ & 34.7 & 47.0 & .000 \\
Fried potatoes (fries and chips) & 21.8 & $18.8-24.8$ & 18.1 & 25.4 & .014 \\
Fast Food & 58.2 & $54.6-61.5$ & 49.5 & 66.8 & .000 \\
Doughnuts/cakes/biscuit & 45.4 & $41.8-48.9$ & 45.6 & 45.2 & .922 \\
Sugary drinks & 1.9 & $1.0-3.0$ & 1.8 & 2.1 & .806 \\
Energy drinks & &
\end{tabular}

Table 4. Multivariate correlates between Physical activity, Sedentary behaviour, unhealthy dietary habits and Sleep time duration $(\mathrm{n}=812)$, The Correlation is significant $(* *$ at the 0.01 level (bilateral), * at the 0.05 level (bilateral)). PA (Physical Activity, SB (Sedentary Behaviour), STD (Sleep Time Duration), D/C (Doughnuts/Cakes), FP: Fried Potatoes (fries and chips), FF (Fast Foods).

\begin{tabular}{|c|c|c|c|c|c|c|}
\hline & & PA & SB & STD & $\mathrm{D} / \mathrm{C}$ & FP \\
\hline \multirow{3}{*}{ SB } & Correlation of Pearson &, $083^{*}$ & 1 & & & \\
\hline & Signification. (Sig) &, 018 & & & & \\
\hline & Number(N) & 812 & 812 & & & \\
\hline \multirow{3}{*}{ STD } & \multirow{3}{*}{$\begin{array}{l}\text { Correlation of Pearson } \\
\text { Signification. (Sig) Number(N) }\end{array}$} &, $078^{*}$ &,$- 087^{*}$ & 1 & & \\
\hline & & ,025 & ,013 & & & \\
\hline & & 812 & 812 & 812 & & \\
\hline \multirow{3}{*}{$\mathrm{D} / \mathrm{C}$} & Correlation of Pearson &,$- 080^{*}$ &, $127^{* *}$ & , $080^{*}$ & 1 & \\
\hline & Signification. (Sig) & ,025 & ,000 & ,026 & & \\
\hline & Number(N) & 812 & 812 & 812 & 812 & \\
\hline \multirow{2}{*}{ FP } & \multirow{2}{*}{$\begin{array}{l}\text { Correlation of Pearson } \\
\text { Signification. (Sig) Number(N) }\end{array}$} &, 012 &, $100^{* *}$ &, 014 &, $165^{* *}$ & 1 \\
\hline & & ,739 &, 005 & ,694 & , 000 & \\
\hline \multirow{3}{*}{ FF } & \multirow{3}{*}{$\begin{array}{l}\text { Correlation of Pearson } \\
\text { Signification. (Sig) Number(N) }\end{array}$} & 039 & $\begin{array}{l}812 \\
076^{*}\end{array}$ & $\begin{array}{l}812 \\
-024\end{array}$ & 812 & $\begin{array}{l}812 \\
296^{* *}\end{array}$ \\
\hline & & 280 & , 035 &, 510 & ,000 & - 000 \\
\hline & & 812 & 812 & 812 & 812 & 812 \\
\hline
\end{tabular}


Sedentary habits include sitting for several habits, such as television viewing (TV), computer using, reading, talking on the phone, and sitting during a car or bus trip, etc. These activities have an energy consumption between one (1.0) and one and half (1.5) Metabolic Equivalent of Task) (METs) (Chau JY, 2013), the guidelines published by the academy Paediatrics for screen time recommend that adolescents should not exceed two 2 (h/d) (American Acad of Paediatrics, 2001).

Our findings revealed that $31 \%$ of adolescents engaged in computer use, and nearly $40 \%$ spend more than 2 hours a day in television viewing, for a similar period. However, television watching time for a duration superior to two hours a day (h/d) among this study (40\%) is somewhat lower than the score of $44 \%$ declared by Hamrani for the Kenitra city adolescent's population (Hamrani, 2015) but it is higher than $30 \%$ reported by El Achhab for Taza city (EL Achhab, 2018), By gender, girls are less physically active and adopt a more sedentary lifestyle than boys. This is consistent with findings from other studies (Saudi and Qatari adolescents) in which boys participated more than girls in PA, while girls spent more time on screen or in a sedentary behaviour than boys (.Al-Nakeeb, 2012); ( Al-Nuaim, 2012); (Al-Thani, 2018) and also with results reported by Hamrani . On the other hand, worldwide ,our prevalence rate of sedentary habits $(40 \%)$ is higher than $24 \%$ reported among Chinese adolescents ( $\mathrm{Li} \mathrm{M}, 2007$ ), and lower than reported in a national survey in the USA, which revealed that $65 \%$ to $67 \%$ of adolescents watched television for more than $2 \mathrm{~h} / \mathrm{d}($ Andersen, 1998). In the present study, adolescents who are physically active also have more periods of sedentary time $(r=.08, p=0.018)$ similar to work of (Jago, 2005). Independently of the low correlation ( $\mathrm{r}=0.08)$ between sedentary habits and moderate physical activity, however, it is not excluded that an individual can accumulate considerable amounts of both sedentary habits and moderate physical activity over a day (Sallis JF,1999) It is noteworthy that the increase in the amount of time spent watching television, playing video games, using computers and surfing in the Internet is a factor that encourages an increase in sedentary behaviour and, consequently, a decrease in physical activity (Temblay, 2011). In another similar study including both adolescents and adults, more than one-third of the adolescent and adult participants were categorized with disproportionately highly SB and yet still met recommended daily PA guidelines (Spittaels, 2012). In addition, there is evidence that most individuals fall into one of the few classes of sedentary habits and physical activity levels. Thus, in one study, most of the participants were divided into three groups: high SB with high PA, low SB with high PA, and moderate SB with low PA (Jago, 2010). It is now admitted that individuals who spent more time in sedentary behaviour are at an increased risk of morbidity and mortality regardless of their level of moderate physical activity (Proper KI,2011). Indeed, it can be said that an adolescent who spends a lot of time using the computer and watching television can later engage in vigorous activities. Therefore, doing too little physical activity and spending more time sitting are fundamentally different concepts.

The present study shows that adolescents who have a high level of PA practice have a significant duration of sleep. Also, among adolescents, insufficient sleep was found to be associated with morning tiredness (Ortega, 2010).

In addition, increasing screens time, viewing television may be a contributing factor to insufficient sleeping time (American Academy of Paediatrics, 2001).

In summary, most adolescents in the present study adopted unhealthy habits, including the consumption of Fried potatoes (fries and chips), fast foods and cakes/biscuits more than three times weekly with very significant differences between girls and boys. The unhealthy eating behaviour is more prevalent in girls and boys which may be explained by the high degree of nutritional transition in our country. Moreover, fast urbanization, overpopulation, the spread of smart TV, increased dependence on computers and communication technologies, and may lead to an inactive lifestyle among adolescents. The continuity of these unhealthy activities increases the risk of adolescents to develop non-communicable diseases because unhealthy habits recognized to be major causes. (Khatib, 2004).

In addition, the study is limited to adolescents in public schools and did not include adolescents in the private sector or with different lifestyle habits.

\section{Conclusion}

The results of this study confirm a very high percentage of physical inactivity, particularly among women (77.94\%) in the region, and a high rate of sedentary behaviour (40\%) among adolescents, or they should be very active at this age, because this phase of adolescence represents a decisive stage in the human life cycle, it is the time when lifestyles are formed and it will be established. 
The government should move to increase the prevalence of PA for the younger generations, who are mostly submerged by smart-phones, high technology equipment, as a side effect of progress in science and globalization. These values are warning signs and highlight the need for effective interventions to improve PA levels in these school-age groups in order to reduce health risk factors and improve long-term health outcomes.

\section{References}

1. Al-Hazzaa, H.M., Musaiger, A.O., \& ATLS Research Group. (2011). Arab Teens Lifestyle Study (ATLS): objectives, design, methodology and implications. Diabetes, metabolic syndrome and obesity: targets and therapy, 4, 417-426.

2. Al-Hazzaa, H.M., Al-Sobayel, H.I., Abahussain, N.A., Qahwaji, D.M., Alahmadi, M.A., \& Musaiger, A.O. (2014). Association of dietary habits with levels of physical activity and screen time among adolescents living in S audi A rabia. Journal of human nutrition and dietetics, 27, 204-213.

3. Allafi, A., Al-Haifi, A.R., Al-Fayez, M.A., Al-Athari, B.I., Al-Ajmi, F.A., Al-Hazzaa, H.M., \& Ahmed, F. (2014). Physical activity, sedentary behaviours and dietary habits among Kuwaiti adolescents: gender differences. Public health nutrition, 17(9), 2045-2052.

4. Al-Nakeeb, Y., Lyons, M., Collins, P., Al-Nuaim, A., Al-Hazzaa, H., Duncan, M.J., \& Nevill, A. (2012). Obesity, physical activity and sedentary behavior amongst British and Saudi youth: a crosscultural study. International journal of environmental research and public health, 9(4), 1490-1506. https://doi.org/10.3390/ijerph9041490.

5. Al-Nuaim, A.A., Al-Nakeeb, Y., Lyons, M., Al-Hazzaa, H.M., Nevill, A., Collins, P., \& Duncan, M.J. (2012). The prevalence of physical activity and sedentary behaviours relative to obesity among adolescents from Al-Ahsa, Saudi Arabia: rural versus urban variations. Journal of nutrition and metabolism, 2012. https://doi.org/10.1155/2012/417589.

6. Al-Thani, M., Al-Thani, A., Alyafei, S., Al-Kuwari, M. G., Al-Chetachi, W., Khalifa, S. E., \& Akram, H. (2018). Prevalence of physical activity and sedentary-related behaviors among adolescents: data from the Qatar National School Survey. Public Health, 160, 150-155.

7. American Academy of Pediatrics. (2001). American Academy of Pediatrics: children, adolescents, and television. Pediatrics, 107(2), 423-426.

8. Andersen, R.E., Crespo, C.J., Bartlett, S.J., Cheskin, L.J., \& Pratt, M. (1998). Relationship of physical activity and television watching with body weight and level of fatness among children: results from the Third National Health and Nutrition Examination Survey. Jama, 279(12), 938-942.

9. Ainsworth, B.E., Haskell, W.L., Herrmann, S.D., Meckes, N., Bassett Jr, D.R., Tudor-Locke, C., \& Leon, A.S. (2011). 2011 Compendium of Physical Activities: a second update of codes and MET values. Medicine \& science in sports \& exercise, 43(8), 1575-1581.

10. Benjelloun, S. (2002). Nutrition transition in Morocco. Public health nutrition, 5(1a), 135-140.

11. Romdhane, HB, Khaldi, R., Oueslati, A., \& Skhiri, H. (2002). Epidemiological transition and food and nutritional transition in Tunisia. Mediterranean Options B, 41.

12. Bull, F.C., Armstrong, T.P., Dixon, T., Ham, S., Neiman, A., \& Pratt, M. (2004). Physical inactivity. Comparative quantification of health risks global and regional burden of disease attributable to selected major risk factors. Geneva: World Health Organization, 729-881.

13. Chau, J.Y., Grunseit, A.C., Chey, T., Stamatakis, E., Brown, W.J., Matthews, C.E., \& van der Ploeg, H. P. (2013). Daily sitting time and all-cause mortality: a meta-analysis. PloS one, 8(11), e80000.

14. El Achhab, Y., Marfa, A., Echarbaoui, I., Chater, R., El-Haidani, A., \& Filali-Zegzouti, Y. (2018). Physical inactivity, sedentary behaviors and dietary habits among Moroccan adolescents in secondary school. Science \& Sports, 33(1), 58-62.

15. Hamrani, A., Mehdad, S., El Kari, K., El Hamdouchi, A., El Menchawy, I., Belghiti, H., \& Aguenaou, H. (2015). Physical activity and dietary habits among Moroccan adolescents. Public health nutrition, $18(10), 1793-1800$.

16. Jago, R., Anderson, C.B., Baranowski, T., \& Watson, K. (2005). Adolescent patterns of physical activity: Differences by gender, day, and time of day. American journal of preventive medicine, 28(5), 447-452. https://doi.org/10.1016/j.amepre.2005.02.007.

17. Jago, R., Fox, K.R., Page, A.S., Brockman, R., \& Thompson, J.L. (2010). Physical activity and sedentary behaviour typologies of 10-11 year olds. International Journal of Behavioral Nutrition and Physical Activity, 7(1), 1-10. https://doi.org/10.1186/1479-5868-7-59

18. Khatib, O. (2004). Noncommunicable diseases: risk factors and regional strategies for prevention and care. EMHJ-Eastern Mediterranean Health Journal, 10(6), 778-788.

19. Li, M., Dibley, M.J., Sibbritt, D.W., Zhou, X., \& Yan, H. (2007). Physical activity and sedentary behavior in adolescents in Xi'an City, China. Journal of Adolescent Health, 41(1), 99-101. 
20. Butte, N.F., Watson, K.B., Ridley, K., Zakeri, I.F., McMurray, R.G., Pfeiffer, K.A., \& Fulton, J.E. (2018). A youth compendium of physical activities: activity codes and metabolic intensities. Medicine and science in sports and exercise, 50(2), 246-256.

21. Omran, A.R. (2005). The epidemiologic transition: a theory of the epidemiology of population change. The Milbank Quarterly, 83(4), 731-57.

22. Ortega, F.B., Chillón, P., Ruiz, J.R., Delgado, M., Albers, U., Álvarez-Granda, J.L., \& Castillo, M.J. (2010). Sleep patterns in Spanish adolescents: associations with TV watching and leisure-time physical activity. European journal of applied physiology, 110(3), 563-573.

23. Owen, N., Healy, G.N., Matthews, C.E., \& Dunstan, D.W. (2010). Too much sitting: the populationhealth science of sedentary behavior. Exercise and sport sciences reviews, 38(3), 105-113.

24. Popkin, B.M. (1994). The nutrition transition in low-income countries: an emerging crisis. Nutrition reviews, 52(9), 285-298.

25. Prochaska, J.J., Sallis, J.F., \& Long, B. (2001). A physical activity screening measure for use with adolescents in primary care. Archives of pediatrics \& adolescent medicine, 155(5), 554-559.

26. Proper, K.I., Singh, A.S., Van Mechelen, W., \& Chinapaw, M.J. (2011). Sedentary behaviors and health outcomes among adults: a systematic review of prospective studies. American journal of preventive medicine, 40(2), 174-182.

27. Sallis, J.F., \& Owen, N. (1999). Physical activity and behavioral medicine. Thousands Oaks. CA: Sage Publications.

28. Spittaels, H., Van Cauwenberghe, E., Verbestel, V., De Meester, F., Van Dyck, D., Verloigne, M., \& De Bourdeaudhuij, I. (2012). Objectively measured sedentary time and physical activity time across the lifespan: a cross-sectional study in four age groups. International Journal of Behavioral Nutrition and Physical Activity, 9(1), 1-12. https://doi.org/10.1186/1479-5868-9-149.

29. Tremblay, M.S., LeBlanc, A.G., Kho, M.E., Saunders, T.J., Larouche, R., Colley, R.C., \& Gorber, S.C. (2011). Systematic review of sedentary behaviour and health indicators in school-aged children and youth. International journal of behavioral nutrition and physical activity, 8(1), 1-22.

30. WHO. Global recommendations on physical activity for health website. http:44399/1/9789241599979_eng.pdf. 2010. (Accessed 17 May 2017).

31. World Health Organization. (2002). The world health report 2002: reducing risks, promoting healthy life. World Health Organization. 